\title{
HIGIENISMO EN EL PERÚ DEL SIGLO XIX. SEBASTIÁN LORENTE Y EL CATECISMO DE HIGIENE
}

\author{
Oswaldo Salaverry ${ }^{1, a}$
}

\begin{abstract}
RESUMEN
El higienismo se manifiesta en el Perú del siglo XIX de diversas maneras y en distintas esferas que trascienden la actividad de los médicos. Sebastián Lorente, médico y educador promovió la educación higiénica de los escolares a través de la publicación de un Catecismo de higiene que tuvo múltiples ediciones en la segunda mitad del siglo. La estructura y contenidos del "Catecismo" se vincula a tradiciones médicas europeas como la interpretación miasmática de la enfermedad, pero también locales como la topografía médica de Hipólito Unanue, ambas en el marco de una visión de imposición de comportamientos "saludables" a la población, que lo asimilan a la obra de Johan Peter Frank.
\end{abstract}

Palabras clave: Higiene; Práctica de salud pública; Historia de la medicina (fuente: DeCS BIREME).

\section{ORTHOPATHY IN 19TH CENTURY PERU: SEBASTIÁN LORENTE AND THE CATECHISM OF HYGIENE}

\begin{abstract}
Orthopathy appeared in Peru in the 19th century in various guises and different spheres that transcended the activities of doctors. Sebastián Lorente, a doctor and educator, promoted hygiene education for schoolchildren through the publication of a Catechism of Hygiene, which went through multiple editions in the second half of the century. The structure and content of the Catechism is linked to European medical traditions such as the miasmatic interpretation of diseases, but also to local traditions like the medical topography of Hipólito Unanue, both of which had a vision of imposing "healthy" behaviors on the population, which assimilated the work of Johann Peter Frank.
\end{abstract}

Key words: Hygiene; Public health practice; History of medicine (source: MeSH NLM).

En el año 1867 se publicó en Lima un pequeño libro del entonces inspector de instrucción pública Sebastián Lorente Ibáñez (1813-1884) cuyo título parecería extraño hoy en día: Catecismo de higiene; el texto, de solo 45 páginas, formaba parte de una ya vasta producción de manuales y textos escolares del mismo autor, quien más que como médico, era conocido como intelectual y político estrechamente vinculado a la educación escolar, especialmente la secundaria.

\section{SEBASTIÁN LORENTE IBAÑEZ}

Lorente procedía de una familia campesina de Alcantarilla, pequeño pueblo de Murcia, España, donde nació en 1813. Sus primeros estudios fueron de Teología en el seminario de la región, luego siguió estudios de Medicina en la Universidad de Valencia, donde se graduó. Sus inquietudes fueron mayores e intentó continuar estudios de Derecho en Madrid, lo que no consiguió ya que se vio postergado, e incluso perseguido, por sus ideas liberales frente al absolutismo español de la época. Sin duda, eso influyó en su decisión de viajar al Perú invitado por Domingo Elías, hacendado iqueño, para incorporarse como profesor de Geografía en el Colegio Nuestra Señora de Guadalupe.

El colegio Guadalupe, entonces de gestión privada, estaba dedicado a la educación primaria; había sido fundado en 1840 por Elías junto con el ciudadano español Nicolás Rodrigo. El joven Lorente llegó a comienzos de 1843; laboró inicialmente como un profesor más, pero luego en 1844, a los 31 años de edad asumió el rectorado del colegio, denominación que correspondía a un coordinador de estudios, dándole un gran impulso:

\footnotetext{
Facultad de Medicina, Universidad Nacional Mayor de San Marcos. Lima, Perú.

Médico cirujano; doctor en Medicina.

Recibido: 16/09/2016 Aprobado: 11/01/2017 En línea: 23/03/2017
}

Citar como: Salaverry O. Higienismo en el Perú del siglo xix. Sebastián Lorente y el Catecismo de higiene. Rev Peru Med Exp Salud Publica. 2017;34(1):13944. doi: 10.17843/rpmesp.2017.341.2776 
incrementó las asignaturas -especialmente las de Historia- a fin de transformar el colegio primario en uno secundario; aunque a costa de un trabajo abrumador, al punto que en 1846 dictaba él mismo más de diez asignaturas. El renovado Colegio Guadalupe se convirtió en el bastión del liberalismo frente al conservadurismo encarnado entonces en el Convictorio de San Carlos con su director Bartolomé Herrera.

Por esa época se incorpora brevemente al Colegio de la Independencia, nombre que había asumido el Real Colegio de Medicina y Cirugía de San Fernando a partir de 1821, en el cual se estaba gestando a la Higiene como disciplina prebacteriana.

Lorente, además, se involucró cada vez más en política. Liberal y militante del Club Progresista junto con Domingo Elías, vio postergadas sus iniciales ambiciones políticas, pero luego, desde el Colegio Guadalupe, contribuyó junto con Elías a la revolución liberal de 1854. Lorente luchó como montonero y, luego de la victoria, con Ramón Castilla como presidente, asumió diversas tareas de gobierno. Fue uno de los principales autores del Reglamento de Instrucción Pública de 1855, que al reorganizar el sistema educativo creó la nueva estructura de la Universidad de San Marcos reincorporando a los colegios universitarios, entre ellos el Colegio de la Independencia, que desde entonces toma el nombre de Facultad de Medicina de San Fernando. Fue nombrado Inspector de Instrucción Pública y encargado de poner en marcha el nuevo Reglamento, pero, además, inició la publicación de una gran cantidad de textos y manuales escolares, que reeditó muchas veces.

Sus libros de Historia son los más conocidos ${ }^{(1-3)}$ pero también redactó libros de Filosofía (4), Geografía (5), Literatura $^{(6)}$, Religión ${ }^{(7)}$, Moral ${ }^{(8)}$, entre otros. Es en ese contexto que publica su Catecismo de higiene.

Fue Antonio Gonzales quien primero usó en el Perú el término "catecismo" para textos escolares. Presentó a Simón Bolívar su propuesta de un Catecismo político para la primera enseñanza de las escuelas de la República del Perú en junio de 1825. El libertador lo aprobó y Gonzales inició una suscripción que, al parecer, no fue suficiente para financiar el texto destinado a los estudiantes de primaria ${ }^{(9)}$.

Este es un denominador común a los textos escolares durante el siglo XIX. Elaborados por intelectuales o profesores, dependían de la buena voluntad de las autoridades, locales o nacionales para que pudieran ser publicados. No fue distinta la suerte de las obras de Lorente. A fines de 1856 pidió un subsidio para reimprimir sus obras de Gramática castellana, Geografía, Filosofía e Historia romana; mencionó que se había abstenido de hacer la solicitud anteriormente por tener un puesto oficial en la Dirección General de Estudios, pero que había cambiado de parecer porque había quienes reproducían sus obras de Geografía y Gramática con numerosos errores. Tuvo la aprobación del director general de estudios, Manuel Ferreyros, en consideración a su "mérito literario y científico" (10), pero, finalmente, no se publicó una nueva edición.

\section{LA HIGIENE EN LA FORMACIÓN MÉDICA DEL SIGLO XIX}

Para ubicar el contexto del folleto que nos ocupa, debemos recordar que, en 1867, Robert Koch recién hacía un año que se había graduado de médico y no sería hasta 1882 que descubriría el agente causal de la tuberculosis; los trabajos de Pasteur recién comenzaban y la era bacteriana no se iniciaba aún. El paradigma médico predominante era el higienismo, que había surgido como un movimiento médico social en la primera mitad del siglo XIX en respuesta a las enfermedades y epidemias que se habían incrementado con el surgimiento de nuevas y más grandes ciudades. La pobreza, el hacinamiento, las pésimas condiciones de abastecimiento de agua y de disposición de excretas eran consideradas la causa inmediata de las enfermedades y epidemias; pero también los hábitos de las personas, y frente a ello se promovió un conjunto de medidas que, por una parte, trataban las enfermedades mediante nuevos establecimientos $y$, por otra trataban, de modificar las condiciones de salubridad de las ciudades, incluyendo el comportamiento de los ciudadanos. Las medidas higienistas fueron adoptadas entusiastamente en toda Europa, aunque se iniciaron en Inglaterra, y se intentaba difundirlas en América.

La interpretación etiológica de la enfermedad estaba entonces aún muy influenciada por el concepto de miasma, un concepto vago que hacía referencia a emanaciones procedentes de la basura y suciedad que, de alguna manera, provocaban enfermedades, especialmente fiebres y pestilencias. La higiene ocupaba, consecuentemente, un lugar importante en la formación médica. Hipólito Unanue la había incorporado como una de las asignaturas del llamado "Quadro Sinóptico" de 1808, que definía las asignaturas que deberían dictarse en el Real Colegio de Medicina y Cirugía de San Fernando. La higiene, para Unanue, era parte de la Medicina Teórica, una de las ramas en que dividió metodológicamente a la formación médica: Medicina Práctica y Medicina Teórica. Esta última comprendía tres conjuntos disciplinarios: Zoonomía, Patología y Psicología. La Higiene, en la interpretación de Unanue, era parte de la Zoonomía (11).

Ya en épocas republicanas, el Colegio de la Independencia mantuvo el plan de estudios virreinal de 
1808; sin embargo, el 10 de octubre de 1826, bajo la presidencia del general Santa Cruz y siendo su ministro Agustín Guillermo Charún, se emitió un Estatuto Provisorio que cambió el plan de estudios y eliminó la asignatura de Higiene. Una nueva modificación del Reglamento interno en 1840 restituyó el curso de Higiene esta vez reunido con Fisiología, antes que Cayetano Heredia asumiera su segundo mandato a cargo del Colegio. Durante el mandato de Heredia, en 1843 se modificó nuevamente el plan de estudios, pero se mantuvo el curso de Fisiología e Higiene, y se dictaba en el segundo año de estudios. Es durante este periodo que Sebastián Lorente ingresó, junto con otros profesores, a la docencia. Dictó los cursos de Historia Natural, Medicina Legal, y Fisiología e Higiene.

Recordemos que Heredia propició que un grupo selecto de sus alumnos viaje a Francia donde continuaron estudios. Entre ellos se encontraba Rafael Benavides, quien precisamente se especializó en Fisiología e Higiene, por lo que, cuando cumpliendo el Reglamento de Instrucción Pública de 1855 se creó la Facultad de Medicina, y se instaló en 1856, Benavides asumió la cátedra de "Física Médica e Higiene" (12).

En agosto de 1861 se promulgó un Reglamento General para la Universidad que estableció las materias que debía dictar cada Facultad; en Medicina se mantuvo la cátedra de "Fisiología e Higiene" (13). En 1876, y bajo la influencia de Lorente, se estableció un nuevo Reglamento General de Instrucción Pública, en el cual se mantuvo la Higiene, pero como cátedra de "Física médica e higiene" (13 p. 110). No hubo otro cambio hasta 1893, fuera del periodo que estudiamos, en cuyo plan de estudios se incluyó la asignatura de "Higiene pública y privada", pero ubicada en el séptimo año de estudios. En los planes anteriores había estado ubicada en los primeros años. Este traslado refleja la influencia del paradigma bacteriano que reemplaza la idea de los miasmas como causa de la enfermedad por la del contagio a través de microorganismos. La higiene continuó siendo importante, pero no como explicación del origen de la enfermedad sino como uno de los medios de ayuda para combatir las fiebres o enfermedades epidémicas.

\section{EL CATECISMO DE HIGIENE}

El libro Catecismo de higiene para las escuelas de instrucción primaria tuvo numerosas ediciones; entre la primera ${ }^{(14)}$ y la sexta y última edición que hemos revisado ${ }^{(15)}$ hubo algunas adiciones, pero mantuvo su estructura básica; algunas ediciones se publicaron, incluso, en un solo volumen con otros "catecismos" del mismo autor, como el Catecismo de economía. Para efectos del presente análisis usaremos la última edición que disponemos y que representa la versión final del autor.

El "catecismo" está estructurado en dieciséis cortas secciones. A las catorce originales de 1867 añadió Lorente dos nuevas secciones en la edición de 1889: Sueño y Longevidad. Cada sección tiene un título e incluye un número variado de apotegmas numerados que suman, en total, 96. Se complementa con una sección de preguntas, una por cada afirmación del catecismo, que sirve para evaluar su adecuada interpretación y recordación. En la tabla 1 se incluye, a modo de ejemplo, un apotegma de cada sección y su respectiva pregunta.

El carácter del higienismo de Lorente es ecléctico, por una parte, se observa la supervivencia de las ideas miasmáticas que eran particularmente sentidas en Lima ${ }^{(16)}$, pero también la influencia de la medicina topográfica y climática de Unanue ${ }^{(17)}$. Ambas interpretaciones no son excluyentes. La idea de miasmas como origen de la enfermedad, de alguna manera remite a una interpretación topográfica: para quienes interpretaban el surgimiento de las enfermedades derivándolas de los miasmas, les es evidente que existen lugares en los que los miasmas naturales, como por ejemplo los dependientes de pantanos o de una excesiva humedad y calor que predisponen a la putrefacción, los convierten en verdaderos focos de difusión de las enfermedades y estos mismos lugares, desde una interpretación climática, al ser investigados topográficamente tienen como una de sus principales características la existencia de esos miasmas. Claro las diferencias son en énfasis; el calor, la humedad, los vientos y otros fenómenos meteorológicos, incluyendo las variaciones barométricas, son fundamentales para una interpretación topográfica-climática, como se manifestó en el Perú del XVIII (18); pero en Lorente se nota una confluencia.

El carácter de "catecismo" en la obra de Lorente no es intrascendente. Aunque liberal en su pensamiento político, Lorente es conservador en materia religiosa, católico; entre sus obras incluye, como ya hemos señalado, obras de moral y religión. Puede interpretarse que su uso de la idea de catecismo en un ámbito totalmente laico, como la higiene personal, toma prestada la idea subyacente a la idea original de catecismo, como expresión de una verdad religiosa, que se muestra, más que se demuestra o enseña, para ser recibida acríticamente, como una verdad revelada. Para Lorente, firmemente convencido del carácter indudable de sus ideas higienistas para beneficio de la población, estos apotegmas y preceptos adquieren el mismo nivel de "verdad revelada", en este caso por la ciencia.

Se emparenta así este "Catecismo de Higiene" con otras iniciativas orientadas a imponer desde la autoridad un comportamiento que se cree firmemente es beneficioso para la población, como ocurre en la 
Tabla 1. Selección de apotegmas del Catecismo de higiene de Sebastián Lorente

\begin{tabular}{|c|c|c|}
\hline Sección & Inciso / número del apotegma en la edición original & Pregunta \\
\hline $\begin{array}{l}\text { Condiciones } \\
\text { personales }\end{array}$ & $\begin{array}{l}\text { 1. La higiene nos enseña a conservar la salud. El que observa las reglas de la } \\
\text { higiene, goza de mejor salud, está menos expuesto a enfermar y puede vivir más } \\
\text { largo tiempo. }\end{array}$ & $\begin{array}{l}\text { ¿Para qué sirve la } \\
\text { higiene? }\end{array}$ \\
\hline Atmósfera & $\begin{array}{l}\text { 15. Deben evitarse los vientos que vienen de lugares impuros, como cementerios } \\
\text { y pantanos, que soplan con mucha fuerza, que son muy destemplados o traen } \\
\text { mucho polvo. }\end{array}$ & $\begin{array}{l}\text { ¿Qué vientos deben } \\
\text { evitarse? }\end{array}$ \\
\hline Climas & $\begin{array}{l}\text { 23. En el Perú se necesitan muchas precauciones para aclimatarse en la montaña, } \\
\text { algunos menos para cambiar la sierra por la costa y solo cuidados en los primeros } \\
\text { días al pasar de la costa a la sierra. }\end{array}$ & $\begin{array}{l}\text { ¿Qué precauciones exigen } \\
\text { los diferentes climas del } \\
\text { Perú? }\end{array}$ \\
\hline Habitaciones & $\begin{array}{l}\text { 28. Los cimientos y paredes deben estar calculados para resistir en los casos } \\
\text { comunes a terremotos e incendios. Las habitaciones deben ser de anchura } \\
\text { moderada, y las ventanas de buena disposición para que entre la luz, se renueve } \\
\text { el aire y no se reciban vientos insalubres. }\end{array}$ & $\begin{array}{l}\text { ¿Qué disposición deben } \\
\text { tener las casas? }\end{array}$ \\
\hline Vestidos & $\begin{array}{l}\text { 37. Debe tenerse especial cuidado de la cama, que es nuestro vestido durante } \\
\text { el sueño y mientras yacemos enfermos. No ha de ser demasiado blanda, ni muy } \\
\text { abrigada; las sabanas han de estar muy limpias, la cabecera un poco levantada, } \\
\text { los colchones sin partes salientes, ni duras; y todo debe airearse diariamente y } \\
\text { renovarse con la frecuencia necesaria. }\end{array}$ & $\begin{array}{l}\text { ¿Qué cuidado se ha de } \\
\text { tener en la cama? }\end{array}$ \\
\hline Baños & $\begin{array}{l}\text { 38. El uso de los baños es de gran importancia para la salud, porque conservan la } \\
\text { limpieza del cuerpo, le fortifican y pueden hacerle más ágil. }\end{array}$ & $\begin{array}{l}\text { ¿Cuál es la importancia de } \\
\text { los baños? }\end{array}$ \\
\hline Cosméticos & $\begin{array}{l}\text { 45. La limpieza de los dientes debe conservarse con polvos, opiatas o líquidos que } \\
\text { no ataquen el esmalte. }\end{array}$ & $\begin{array}{l}\text { ¿Cómo debe conservarse } \\
\text { la limpieza de los dientes? }\end{array}$ \\
\hline Excreciones & $\begin{array}{l}\text { 46. Debe cuidarse de las excreciones propias del cuerpo; porque siendo excesivas, } \\
\text { debilitan y cuando se perturban, pueden causarse graves enfermedades. }\end{array}$ & $\begin{array}{l}\text { ¿Qué cuidado se ha de } \\
\text { tener de las excreciones? }\end{array}$ \\
\hline Alimentos & $\begin{array}{l}\text { 62. Además de la moderación en los alimentos es necesario no tomarlos después } \\
\text { de agitaciones violentas de cuerpo o de espíritu, masticarlos bien, y no turbar la } \\
\text { digestión con baños fríos, ejercicios violentos o cualquier otro exceso. }\end{array}$ & $\begin{array}{l}\text { ¿Cuáles son las } \\
\text { principales precauciones } \\
\text { antes y después de la } \\
\text { comida? }\end{array}$ \\
\hline Bebidas & $\begin{array}{l}\text { 66. El aguardiente de uva, el de caña, el de frutas y otros que se consiguen por la } \\
\text { destilación, tiene una actividad peligrosa; por lo que solo en muy limitada cantidad } \\
\text { y en casos bien determinados, dejan de causar mucho daño. }\end{array}$ & $\begin{array}{l}\text { ¿Con qué precauciones } \\
\text { pueden usarse las bebidas } \\
\text { destiladas? }\end{array}$ \\
\hline Ejercicio & $\begin{array}{l}\text { 71. La gimnástica que regulariza el ejercicio, debe formar parte de la educación, } \\
\text { para que el cuerpo se desarrolle bien y se impidan los malos efectos de los } \\
\text { trabajos intelectuales excesivos. }\end{array}$ & $\begin{array}{l}\text { ¿Cuál es la importancia de } \\
\text { la gimnasia? }\end{array}$ \\
\hline Percepciones & $\begin{array}{l}\text { 75. Cuando no llega a ser muy perjudicial, es por lo común inútil el uso habitual } \\
\text { del tabaco, la coca y el opio que, si bien procuran cierta distracción y pueden } \\
\text { tener ventajas excepcionales, nos imponen necesidades facticias cada día más } \\
\text { imperiosas y conducen a abusos muy nocivos. }\end{array}$ & $\begin{array}{l}\text { ¿Por qué debe evitarse el } \\
\text { uso habitual del tabaco, la } \\
\text { coca y el opio? }\end{array}$ \\
\hline Preservativos & $\begin{array}{l}\text { 83. Es una falta de humanidad y de previsión despreciar la vacuna que preserva } \\
\text { del terrible azote de las viruelas. }\end{array}$ & $\begin{array}{l}\text { ¿Qué aprecio debe } \\
\text { hacerse de la vacuna? }\end{array}$ \\
\hline
\end{tabular}

Fuente: Lorente $S^{(15)}$

propuesta de Johan Peter Frank y su Medizinischen Polizey o policía médica ${ }^{(19)}$. La idea o pretensión de mejorar la salud pública imponiendo comportamientos a la población es un tema de debate que no se agotó en el siglo XVIII o XIX, constantemente es reactualizado en diferentes circunstancias. Puede identificarse en la propuesta y ejecución de medidas compulsivas como las vacunaciones forzadas antivariolosas a inicios del siglo $\mathrm{XX}$, y en formas perversas como la esterilización forzada de mujeres en el Perú a fines del mismo siglo ${ }^{(20)}$.

Si bien el Catecismo de higiene de Lorente no tuvo continuidad, es un ejemplo de los esfuerzos iniciales de mejorar la salud pública, "perfeccionando" al ciudadano 
en el Perú de fines del XIX. Sobre la naturaleza de estos esfuerzos "perfeccionadores" a partir de la autoridad, podemos remontarnos, como sustento teórico de los mismos, al carácter mismo de la higiene, vista como expresión de una superioridad de la clase dirigente de un pueblo en épocas premodernas ${ }^{(21)}$, pero que luego ya con el surgimiento del higienismo se intenta extender a la población general, precisamente a través de medidas incluso coercitivas. La reflexión teórica sobre este tema debe mucho a la obra de Foucault ${ }^{22)}$; pero también es interpretable por razones mucho más simples de interés del Estado, como por ejemplo el poblacionismo del siglo XVIII y XIX, que centraba el poder de un Estado en el tamaño de su población, pero de población apta para la producción y para la guerra. Desde la perspectiva de la ciencia esta idea del perfeccionamiento del ser humano trasciende los temas de salud ya que tal como lo refiere Ten:

If we could suppose a new people, a generation of children: the legislator, finding no expectations formed which could oppose his views, might fashion them as his pleasure, as the sculptor fashions a block of marble ${ }^{(23)}$.

Si pudiéramos imaginar un nuevo pueblo, una generación de niños: el legislador, no encontrando ninguna expectativa previa que pudiera oponerse a sus puntos de vista, podría modelarlos a su placer, como el escultor que modela un bloque de mármol.

Una reflexión final sobre el Catecismo debe recaer en el tema de cómo se ha continuado desde el Estado, y específicamente desde el sector Salud, la tarea de promover en la población condiciones y comportamientos higiénicos. Hace ya muchos años que la visión constructivista de la educación nos ha alejado de instrumentos como el "catecismo de higiene", y los resultados que obtenemos cuestionan el éxito de los actuales esfuerzos: los hábitos higiénicos ya no son un objetivo central de la formación escolar, esta labor se ha delegado al sector Salud. Desde este sector, la comunicación en salud, que debería ser la heredera natural de los esfuerzos de Lorente y su generación, no tiene una política definida y se encuentra al albedrío de las diferentes gestiones. En ningún caso se toca siquiera el tema de la necesaria e imprescindible adaptación cultural de la comunicación en salud, y no nos referimos solamente a la que corresponde a la diversidad étnica de nuestro país, que es por sí misma un tema pendiente, sino a las diversas subculturas urbanas derivadas del complejo desarrollo social.

Existen jóvenes que deben ser instruidos en salud sexual y reproductiva, pero los índices de embarazo adolescente nos señalan el fracaso de la comunicación, probablemente porque los códigos y medios usados no corresponden a la subcultura juvenil urbana y a la rural en forma diferenciada. Similar análisis se puede realizar a los recientes brotes y posibles epidemias de enfermedades como el dengue, la chikungunya y el Zika; todas ellas, para ser controladas, necesitarían un cambio de comportamiento higiénico de los integrantes de la comunidad, pero los resultados, incluso con resistencia activa a las medidas desplegadas por el sector Salud, también evidencian una falla en la comunicación.

Tal vez sería menester revisar, en una visión moderna y menos autoritaria, la pertinencia de retornar a instrumentos como el Catecismo de higiene de Sebastián Lorente.

Fuentes de financiamiento: autofinanciado.

Conflicto de interés: el autor declara la ausencia de conflictos de interés.

\section{REFERENCIAS BIBLIOGRÁFICAS}

1. Lorente S. Historia del Perú bajo los Borbones, 1700-1821. Lima: Librería de Gil y Aubert; 1871.

2. Lorente S. Historia del Perú bajo la dinastía austriaca, 1598-1700. Paris: Imprenta de A. E. Rochette; 1870.

3. Lorente S. Historia de la conquista del Perú. Lima: Librería de Masías; 1861.

4. Lorente S. Compendio de Filosofía, para los colegios del Perú. Lima. Librería de Masías; 1860.

5. Lorente S. Primeras lecciones de geografía para las escuelas y colegios del Perú. Lima: Aubert y Cía.; 1869.

6. Lorente S. Nociones de estilo: libro de lectura que comprenden trozos escogidos de los mejores autores y las principales reglas de composición. $4^{\circ}$ edición. Lima: Benito Gil; 1888.

7. Lorente S. Catecismo dogmático que comprende la religión demostrada y la doctrina cristiana para el Colegio de Guadalupe. Lima: Aubert y Cía.; 1867.

8. Lorente S. Catecismo de moral y urbanidad, para las escuelas populares. Lima: Benito Gil; 1882.

9. Espinoza G. Libros escolares y educación primaria en la ciudad de Lima durante el siglo XIX. Histórica. 2007;31(1):135-70.

10. Expediente promovido por Sebastian Lorente ante el director general de estudios. AGN. J-3, Leg. 183. 1856.
11. Unanue H. Quadro sinóptico de las ciencias que se enseñaran en el Colegio de Medicina de San Fernando. Lima: Minerva Peruana; 1808.

12. Bustíos C. Educación médica y su contexto: Facultad de Medicina de San Fernando. Perú 1856 - 1969. Lima: UNMSM; 2006.

13. Delgado G. Rabi M. Evolución histórica de la Facultad de Medicina. Lima: UNMSM; 2006.

14. Lorente S. Catecismo de higiene para las escuelas de instrucción primaria. $2 \mathrm{da}$ edición. Lima: Aubert y Loiseau.; 1867.

15. Lorente $S$. Catecismo de Higiene para las Escuelas de Instrucción Primaria. 
6ta edición. Lima: Benito Gil Editor; 1889.

16. Rivasplata P. El clima "miasmático" limeño según algunas percepciones de autoridades, médicos y viajeros durante los siglos XVI al XIX. Temas americanistas. 2015; 34:76-8.

17. Salaverry O. Hipólito Unanue y la medicina topográfica. Acta Herediana. 2016; 57(1): 33-41. doi: 10.20453/ ah.v57i0.2798.

18. Salaverry O. Los orígenes del pensamiento médico de Hipólito
Unanue. An Fac Med Lima. 2005;66(4):357-70.

19. Frank JP. System einer vollständigen medizinischen Polizey. Berlin: Friedrich Bieweg; 1792.

20. Ballon A. Memorias del caso peruano de esterilización forzada. Lima: Fondo editorial Biblioteca Nacional del Perú, 2014.

21. Porter D. Health, Civilization and State. A history of public health from ancient to modern times. London: Routledge; 1999.
22. Foucault M. Microfísica del poder. Madrid: Ediciones La Piqueta; 1993.

23. Bebtham J. Principles of the Civil Code. Pat 1, Chapter 17. En: Bowring J. The Works of Jeremy Bentham. Vol 11. Edinburgh: J. William TaitSimpkin, Marshall \& Co.; 1843.

Correspondencia: Oswaldo Salaverry García. Dirección: Nicolás de Aranibar 537, Santa

Beatriz. Lima, Perú.

Teléfono: (+51) 997896697

Correo electrónico: osalaverryg@unmsm.edu.pe

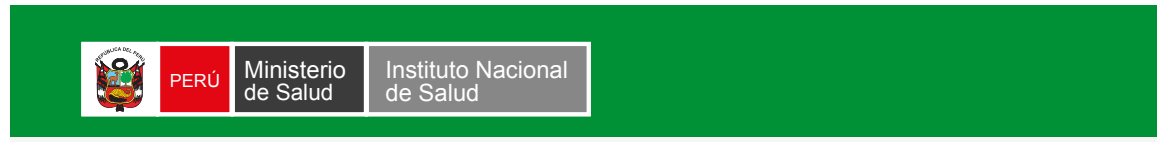

Inclusión social en salud: aporte de las tecnologías de diagnóstico para enfermedades desatendidas

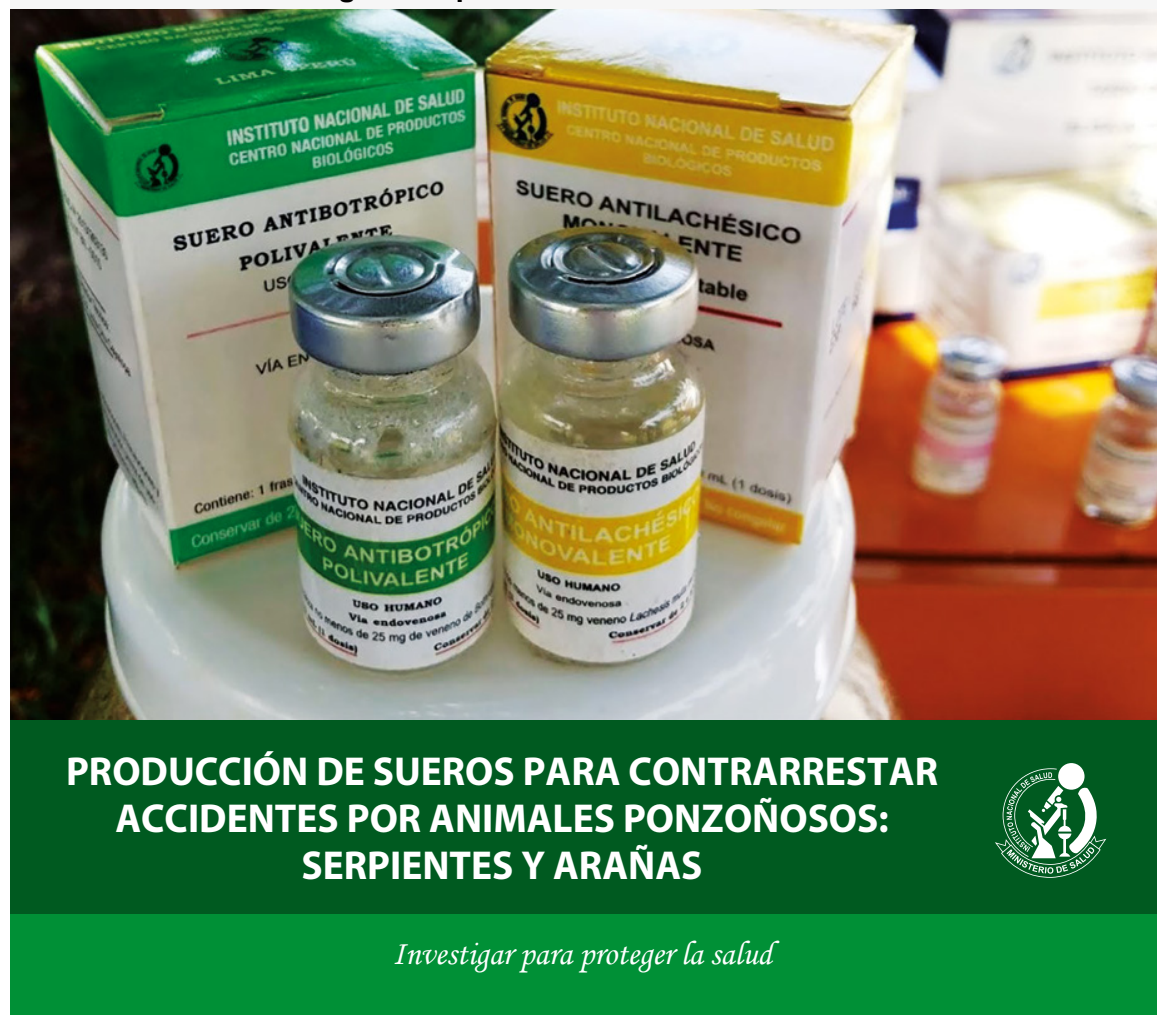

